\title{
A VIABILIDADE DO SISTEMA DE GESTÃO DA SUSTENTABILIDADE (SGA) EM MEIOS DE HOSPEDAGEM
}

\section{THE VIABILITY OF THE SUSTAINABILITY MANAGEMENT SYSTEM (SMS) IN HOSTING COMPANY}

\section{Josi Rosa de Oliveira}

Professora-Tutora Externa no Centro Universitário Leonardo Da Vinci - UNIASSELVI. E-mail: josi.montanet@gmail.com

\section{Scheila Rigotti}

Professora-Tutora Externa no Centro Universitário Leonardo Da Vinci - UNIASSELVI. E-mail: scheilarigotti@yahoo.com.br

\section{RESUMO}

O turismo é um dos maiores segmentos econômicos do planeta, e o desenvolvimento não controlado de um ponto turístico pode levar ao esgotamento de seus recursos naturais, à deterioração de seu patrimônio cultural e ao desequilíbrio social. Nesse contexto e na temática da sustentabilidade, procurou-se neste texto abordar a viabilidade do sistema de gestão da sustentabilidade em meios de hospedagem. Para tanto, a pesquisa, de natureza qualitativa, utilizou-se de meios bibliográficos e documentais para a busca de informações. Como resultados e perante as preocupações de um desenvolvimento descontrolado, destaca-se o turismo sustentável como uma alternativa correta, assegurando um sistema de gestão ambiental nos meios de hospedagens em conformidade com a Norma Brasileira ABNT 15401, que aborda um sistema de gestão baseado nas três dimensões da sustentabilidade: ambiental, sociocultural e econômica, ressaltando-se a necessidade e o compromisso de estudos futuros e amplos abordando os indicadores de sustentabilidade.

Palavras-chave: Sistema de gestão ambiental. Norma ABNT 15401. Turismo sustentável. Meios de hospedagens.

\begin{abstract}
Tourism is one of the largest economic segments of the planet, and the uncontrolled development of a tourist spot can lead to the depletion of its natural resources, deterioration of its cultural heritage and social unbalance. In this context and in the theme of Sustainability, this text sought to address the viability of the Sustainability Management System in lodging environments. For this, the qualitative research used bibliographical and documentary means to search for information. As a result and faced with the concerns of uncontrolled development, sustainable tourism stands out as a correct alternative, ensuring an environmental management system in the lodging facilities in accordance with Brazilian Standard ABNT 15401 that addresses a management system based on the three dimensions of environmental, socio-cultural and economic sustainability, highlighting the need and commitment of future and broad studies addressing sustainability indicators.
\end{abstract}

Keywords: Environmental management system. Standard ABNT 15401. Sustainable tourism. Means of lodging. 


\section{INTRODUÇÃO}

O turismo vem passando por um alto crescimento nas últimas décadas e, como outros segmentos, tem um vasto potencial de impacto ambiental e poluidor. Sua prática mal planejada pode levar ao esgotamento dos recursos naturais da região onde o destino turístico está localizado.

O turismo sustentável surgiu a fim de proteger esses destinos a longo prazo, buscando que todos os meios envolvidos em torno dessa atividade desenvolvam práticas ambientais que possam promover um desenvolvimento sustentável.

Os meios de hospedagem são diretamente ligados a essa atividade, pois representam o maior setor dentro da economia turística, sendo peça-chave no processo de desenvolvimento sustentável dos destinos turísticos. A Norma ABNT 15401 foi desenvolvida com o objetivo de estabelecer os requisitos para que os meios de hospedagens possam planejar um sistema de gestão ambiental, voltado a práticas sustentáveis em concordância com os principais modelos de gestão conhecidos pela ABNT.

O SGA tende a proporcionar significantes melhorias no desenvolvimento ambiental, econômico e social do empreendimento em se adotando um sistema de gestão ambiental planejado para que se atenda aos requisitos da norma ABNT 15401, em conformidade com a legislação específica para o empreendimento.

\section{OS MEIOS DE HOSPEDAGENS E O TURISMO SUSTENTÁVEL}

O turismo é uma das maiores atividades econômicas do mundo, e, conforme tem observado a Empresa de Turismo Brasileira (EMBRATUR), o Brasil vem evoluindo de forma gradativa no ranking da Organização Mundial do Turismo (OMT) e se tornando um dos destinos mais procurados.

Com esse crescimento, ocorreu a preocupação de um desenvolvimento não controlado de um destino turístico que poderia causar um esgotamento de seus recursos naturais, patrimônio histórico e a comunidade envolvida. Em consequência, surge o turismo sustentável como alternativa para assegurar um desenvolvimento controlado sem causar impactos futuros na região.

Segundo Inskeep (1991, p. 461), o desenvolvimento sustentável do turismo pode ser percebido como "uma forma de conhecer e satisfazer as necessidades presentes dos turistas e das regiões receptoras, protegendo e garantindo as oportunidades futuras”. 
O turismo sustentável surgiu a partir do conceito intitulado no Relatório de Bruntland e propõe que o desenvolvimento sustentável "[...] é aquele que atende às necessidades dos turistas de hoje e das regiões receptoras, ao mesmo tempo em que protege e amplia as oportunidades para o futuro".

Para a Organização Mundial do Turismo,

[...] o desenvolvimento sustentável do turismo é um processo contínuo que requer monitoramento constante dos impactos que a atividade pode causar, de modo que, com ações de manejo, seja possível minimizar os impactos negativos e maximizar os benefícios potenciais, introduzindo medidas preventivas ou de correção de rumos. Esse processo requer a participação e o comprometimento de todos os atores envolvidos com o turismo, principalmente o poder público, que deve incentivar e apoiar o processo, estimulando a participação da sociedade por meio da construção de consensos. Portanto, os produtos turísticos sustentáveis são desenvolvidos em harmonia com o meio ambiente e culturas locais, de forma que estes se convertam em permanentes beneficiários, e não meros espectadores de todo o processo (OMT, 2004).

Os meios de hospedagens são um setor importante do turismo, pois, para que a viagem seja realizada, além do deslocamento, é indispensável que exista um local para acomodação dos turistas. Essenciais para o crescimento do turismo, os meios de hospedagens necessitam planejar uma infraestrutura hoteleira visando ao conceito do turismo sustentável, uma vez que essa atividade pode gerar, assim como o turismo, vários impactos para o meio ambiente e as comunidades locais. (OMT 2004)

Como sugere Vieira:

\begin{abstract}
A hotelaria é um segmento que está muito propenso a desperdiçar. A grande maioria dos hóspedes ainda não tem uma consciência voltada para a economia. Cuidados com detalhes que podem parecer pequenos, para um hotel poderão representar gastos incalculáveis como: banho demorado, água correndo no lavatório sem preocupação com o consumo que isso representa, ar-condicionado funcionando com portas e janelas abertas e outras formas de desperdiçar que fogem do controle da gerência (2004, p. 9).
\end{abstract}

Os meios de hospedagens poderão auxiliar na mudança de hábitos, desde que seja planejado seu sistema de gestão com os princípios do desenvolvimento sustentável.

Como afirma a Tour Operators' Initiative for Sustainable Tourism Development:

A chave para um SGA bem-sucedido e eficiente é assegurar o pleno apoio, a contribuição e a participação de todas as pessoas envolvidas, inclusive funcionários, hóspedes, parceiros comerciais e comunidades locais. O compromisso dos funcionários e a participação devem vir de todas as partes da organização, não só da alta gerência. A educação dos hóspedes também é parte importante de um SGA eficiente, visto que muitos dos seus componentes, tais como os atos de apagar as luzes e desligar outros aparelhos elétricos, usar menos água ou evitar produtos locais insustentáveis, vão exigir apoio ativo dos hóspedes (TOI, 2003). 
Em sistemas de gestão, é muito importante essa participação e comprometimento de todos para o sucesso do empreendimento, independente do ramo de atividade.

\section{ABNT NBR 15401}

A Norma Brasileira ABNT 15401 foi criada em 2006, sendo atualizada em 2014, desenvolvida com objetivo de estabelecer requisitos para que os meios de hospedagens tenham condições de planejarem e operarem suas atividades conforme os princípios estabelecidos para o turismo sustentável, tendo sido redigida de forma a aplicar-se a todos os tipos e portes de empreendimentos, adequando-se a diferentes condições geográficas, culturais e sociais, mas com atenção particular à realidade e à aplicabilidade às pequenas e médias empresas.

Essa norma pode ser aplicada a qualquer meio de hospedagem que deseje:

a) implementar, manter e aprimorar práticas sustentáveis para as suas operações;

b) assegurar-se de sua conformidade com a política de sustentabilidade definida;

c) demonstrar tal conformidade a terceiros;

d) buscar a certificação segundo esta Norma por uma organização externa; ou

e) realizar uma autoavaliação da conformidade com essa norma.

A norma é baseada em estabelecer um sistema de gestão sustentável, tendo como principais referências os modelos de gestão da NBR ISO 9001 (sistema de gestão da qualidade), NBR ISO 14001 (sistema de gestão ambiental) e NBR ISO 14900 (sistema de gestão da análise de perigos e pontos críticos de controle, que trata da segurança dos alimentos).

Esse sistema

especifica os requisitos relativos à sustentabilidade de Meios de Hospedagem, estabelecendo critérios mínimos específicos de desempenho em relação à sustentabilidade e permitindo a um empreendimento formular uma política e objetivos que levem em conta os requisitos legais e as informações referentes aos impactos ambientais, socioculturais e econômicos significativos (ABNT, 2006).

Seus princípios são:

a) respeitar a legislação vigente;

b) garantir os direitos das populações locais;

c) conservar o ambiente natural e sua biodiversidade; 
d) considerar o patrimônio cultural e valores locais;

e) estimular o desenvolvimento social e econômico dos destinos turísticos;

f) garantir a qualidade dos produtos, processos e atitudes;

g) estabelecer o planejamento e a gestão responsáveis.

\section{SISTEMA DE GESTÃO AMBIENTAL}

Os SGAs (Sistema de Gestão Ambiental) surgiram como uma importante ferramenta gerencial aos empresários que buscavam mudanças estratégicas voltadas ao conceito do desenvolvimento sustentável em suas organizações.

A ISO define SGA como:

[...] é um meio gerencial que as empresas dispõem para obter o controle e o acompanhamento organizacional ambiental. Pode ser entendido como um conjunto de ações (procedimentos e controles) e recursos (humanos, financeiros, materiais) organizados e que tem como objetivo garantir que os produtos e atividades da empresa sejam ecologicamente corretos. É um sistema criado para implementar e acompanhar as atividades de proteção ambiental. Suas diretrizes são: organizar, planejar, atribuir responsabilidade, prever recursos materiais e humanos, determinar procedimentos para atender assim, a uma "Política Ambiental" e as expectativas de desempenho, conforme as exigências da ISO 14001 (ABNT, 2001, p.2).

Um SGA, quando bem implantado e monitorado, tende a proporcionar significantes benefícios nos custos da empresa, melhorar sua imagem empresarial voltada a questões ambientais, além de se tornar uma empresa mais ética e com responsabilidade social.

Como citado por Darnall et al.:

A adoção de práticas de gestão ambiental altera profundamente o desempenho ambiental e econômico da organização ou destino, assim como seu relacionamento com fornecedores, consumidores, empregados, agências de financiamento e reguladores das políticas ambientais (2001, p. 56, tradução do autor)

Os meios de hospedagens devem assegurar um SGA buscando um atendimento continuado e sistemático dos princípios do turismo sustentável, em que se estabelecem os seguintes requisitos:

a) política de sustentabilidade: fixa os princípios gerais da organização e determina um senso geral de orientação para as ações de todos os setores;

b) responsabilidade da direção: assegura que as funções, responsabilidade e autoridades no empreendimento sejam definidas, documentadas e comunicadas, a fim de facilitar uma gestão eficaz; 
c) planejamento: define um conjunto de procedimentos a partir de um levantamento de quais aspectos serão gerenciados, conforme estabelecido através de um mapeamento dos aspectos ligados à sustentabilidade, estabelecendo um conjunto de objetivos e metas documentadas;

d) implementação e operação: momento em que se iniciam as atividades definidas na fase do planejamento;

e) verificação e monitoramento: deve se monitorar e medir periodicamente as operações e atividades que possuem algum impacto significativo sobre a sustentabilidade e para avaliação do atendimento a legislação e regulamentação pertinentes;

f) ações corretivas.

\section{ROTEIRO DE IMPLEMENTAÇÃO DE UM MODELO DE GESTÃO}

O modelo de implementação foi desenvolvido a partir de um sistema de gestão baseado no ciclo PDCA, tendo como referência os requisitos da Norma Brasileira ABNT 15401.

O cliclo PDCA é uma metodologia que teve seu desenvolvimento realizado por Walter A. Shewart, na década de 1930, e sua consolidação realizada por William Edward Deming, a partir da década de 1950, após a Segunda Guerra Mundial em empresas japonesas visando à qualidade dos processos com minimização de custos e desperdícios (PACHECO et al., 2010).

As letras PDCA originam-se do inglês e nomeiam as etapas do ciclo que são: "Plan", planejar; "Do", fazer ou executar; "Check", checar; e "Action", agir de forma corretiva (PACHECO et al., 2010).

Já Campos (1996, p.262) define o ciclo PDCA como o método de melhorias, “o PDCA é um método de gerenciamento de processos ou de sistemas. É o caminho para se atingirem as metas atribuídas aos produtos dos sistemas empresariais".

O ciclo PCDA é dividido em quatro passos: planejamento, implementação e operação, verificação e monitoração, ação corretiva. A seguir, apresentamos os passos descritos por Campos (1996).

\section{Planejamento}


Essa etapa é considerada a mais importante por ser no início, e a eficácia futura do ciclo estará baseada em um planejamento bem elaborado e detalhado.

$1^{\circ}$ Diagnóstico no sistema de gestão da sustentabilidade, verificando se o meio de hospedagem já realiza alguma prática ambiental, para que se possa identificar onde são necessárias as melhorias ou execução de outras atividades voltadas para o atendimento da ABNT NBR 15401.

$2^{\circ}$ Mapeamento das atividades, em que conheceremos como se organiza o fluxo das atividades de cada setor do meio de hospedagem (ABNT NBR 15401).

$3^{\circ}$ Identificar os aspectos e impactos ambientais para analisar possíveis impactos (positivos ou negativos) das atividades executadas no passado, presente ou futuro, tomando medidas necessárias para diminuir os impactos negativos.

$4^{\circ}$ Requisitos legais e outros requisitos. O empreendimento deverá conhecer e aplicar a legislação identificada de acordo com as atividades realizadas. Essa documentação deve ser cumprida e entendida por todos no meio de hospedagem.

$5^{\circ}$ Política de sustentabilidade, em que, a partir de uma declaração, o meio de hospedagem deverá apresentar suas diretrizes e os rumos a serem seguidos por seus colaboradores, permitindo que todas as partes interessadas façam seu trabalho e possam desfrutar das atividades sustentáveis que venham a ser executadas. A política de sustentabilidade deverá ser documentada, comunicada e entendida por todos no empreendimento.

$6^{\text {o }}$ Definição de objetivos e metas, essencial ao SGA, pois estabelece aonde queremos chegar no planejamento. As metas e objetivos podem ser aplicadas a todos os setores da organização. É recomendado escolher um time de colaboradores apropriados para cada função, para se definir objetivos e metas de acordo com cada setor específico. Cada meta deverá ter um prazo determinado para se realizar. Após definidos e documentados os objetivos e metas, é recomendado que a organização obtenha um indicador de desempenho ambiental, para que seja feito o controle e medição de desempenho de suas atividades (ABNT NBR 15401).

$7^{\circ}$ Responsabilidade da direção. É importante que se tenha um responsável da direção pelo sistema de gestão ambiental no meio de hospedagem, a fim de desempenhar ou coordenar as atividades necessárias para o cumprimento dos requisitos instituídos na ABNT NBR 15401. 
$8^{\circ}$ Programa de gestão da sustentabilidade, em que o empreendimento estabelece um plano de ação, o qual contará a tarefa a ser realizada, o prazo de início e fim da atividade, o responsável para realizá-la e os detalhes de como a tarefa será executada. Semanalmente ou a cada quinze dias, é importante verificar como anda o Plano de Ação, visando ao controle, melhoria e correções (ABNT NBR 15401).

$9^{\circ}$ Competência, conscientização e treinamento. Necessário para avaliar o nível de conhecimento e habilidade dos colaboradores. Se a qualificação não for suficiente de acordo com a necessidade para se realizar os objetivos e metas, o colaborador deverá desenvolver um programa de desenvolvimento de competências que incluirá ações de treinamento e/ou qualquer outro tipo de ação para o desenvolvimento desejado.

\section{Implementação e operação}

Nessa etapa, todas as metas e objetivos especificados na etapa anterior e devidamente formalizados nos planos de ações deverão ser colocados em prática. A organização deverá comunicar seu sistema de gestão ambiental aos funcionários nos vários níveis e funções do empreendimento, comunicando também ao público externo sobre suas ações sustentáveis.

É essencial que o empreendimento tenha controle eficiente da sua documentação do sistema de gestão, para assegurar que possam ser localizados, analisados e revisados quando necessários, para manter os registros dos treinamentos e experiência dos colaboradores e avaliar a eficácia das ações executadas e manter os registros delas.

Através da medição regular e adequada dos itens de controle, que poderão estar locados no gerenciamento da rotina ou poderão estar sendo gerados quando uma nova meta for estipulada, a empresa poderá contemplar com mais exatidão as metas propostas no plano de ação. Todos esses itens de controle geram no processo itens de verificação, os quais podem ser definidos, segundo Campos (2004), como medidores do desempenho dos componentes do processo, ou seja, os itens de verificação atuam sobre as causas (incidem sobre o processo).

\section{Verificação e monitoramento}


A terceira etapa do ciclo do PCDA é definida como a fase da verificação das ações implementadas na etapa anterior. O monitoramento e medição são realizados através de dados analisados dos indicadores de desempenho ambientais e documentos com resultados de suas ações implementadas, com o propósito de verificarmos se o meio de hospedagem está cumprindo com seus objetivos e metas. Essa análise deverá ser registrada em um relatório ou em uma ata de reunião.

\title{
Ações corretivas e preventiva
}

A última etapa é caracterizada por identificar através dos monitoramentos e medições os resultados não satisfatórios e as possíveis melhorias para essas atividades a partir de ações corretivas.

\section{INDICADORES PARA O SISTEMA DE GESTÃO DA SUSTENTABILIDADE}

Os indicadores ambientais possibilitam aos meios de hospedagens verificarem seu desempenho no termo das três dimensões envolvidas na sustentabilidade, ambiental, sociocultural e econômica, e tem como função auxiliar o empreendimento através de um monitoramento ao longo do tempo do seu progresso e identificando melhorias necessárias à sua gestão.

A European Green Table definiu, em 1993, que

\begin{abstract}
Indicadores de Desempenho Ambiental são medições da proficiência de uma empresa em proteger o meio ambiente e que podem ser interpretados como medidas que descrevem o modo como uma organização gerencia seus impactos ambientais (JOHNSTON et al., 2001, p. 2).
\end{abstract}

O sistema de indicadores proposto para o sistema de gestão em meio de hospedagem é composto de 12 indicadores, quatro para cada dimensão da sustentabilidade. Esses indicadores apresentam uma coleta de dados e um método de cálculo para que possamos avaliar estatisticamente seu desempenho ambiental.

Define-se avaliação de desempenho ambiental como sendo o processo formal de selecionar indicadores de forma a medir, analisar, estimar, reportar e comunicar o resultado ambiental da organização segundo seus critérios de desempenho (SEIFERT, 2005, p. 3).

Indicadores propostos em dimensão ambiental:

a) consumo de água/hóspede/noite; 
b) consumo de energia/hóspede/noite;

c) geração de resíduo/hóspede/noite;

d) $\%$ do faturamento bruto aplicado em iniciativas ambientais.

Indicadores propostos em dimensão sociocultural:

a) \% mão de obra local;

b) \% do faturamento bruto aplicado em iniciativas socioculturais;

c) quantidade de horas de treinamento/colaborador $(\mathrm{H} / \mathrm{h})$;

d) $\%$ de rotatividade da mão de obra.

Indicadores propostos em dimensão econômica:

a) \% de satisfação do cliente;

b) índices de acidentes (sem afastamento e com afastamento);

c) taxa de ocupação;

d) taxa de ocupação (break even point).

\section{REQUISITOS PARA O TURISMO SUSTENTÁVEL}

O desenvolvimento sustentável é hoje um objetivo global, envolvendo organizações não governamentais, empresas privadas, governos e a sociedade em geral. Construir processos sustentáveis implica em realizar, sistematicamente, ações que visam não só a preservar os ecossistemas e a biodiversidade, mas também a melhorar as condições socioeconômicas das comunidades nas quais a organização está inserida.

Um grande número de ferramentas, incluindo diversas certificações, está disponível para o gestor que deseja produzir de forma sustentável. No entanto, a sustentabilidade apoiase sempre em três pilares: o econômico, o social e o ambiental.

A seguir, serão abordados os principais requisitos para o turismo sustentável.

\section{REQUISITOS AMBIENTAIS}

As práticas do empreendimento devem ser sustentáveis e com função de diminuir a degradação do ambiente. Os requisitos ambientais servem como meio de consulta para orientação e implementação do sistema de gestão ambiental que está descrito na ABNT NBR 15401.

Os requisitos ambientais são: 

a) preparação e atendimento a emergência ambientais;
b) áreas naturais, flora e fauna;
c) arquitetura e impactos da construção no local;
d) paisagismo;
e) emissões, efluentes e resíduos sólidos;
f) eficiência energética;
g) conservação e gestão do uso de água.

\section{REQUISITOS SOCIOCULTURAIS}

Os requisitos socioculturais deverão contribuir para que as operações e práticas do empreendimento respeitem o patrimônio cultural da região e suas tradições, ajudando no desenvolvimento social e econômico dos trabalhadores e comunidades envolvidas na cadeia produtiva.

Os requisitos socioculturais são:
a) comunidades locais;
b) trabalho e renda;
c) condições de trabalho;
d) aspectos culturais;
e) saúde e educação;
f) populações tradicionais.

\section{REQUISITOS ECONÔMICOS}

Os requisitos econômicos envolvem as práticas econômicas do empreendimento ao que devem ser seguras, viáveis e satisfazer às expectativas do cliente, atendendo à legislação pertinente.

Os requisitos econômicos são:

a) viabilidade econômica do empreendimento;

b) qualidade e satisfação dos clientes;

c) saúde e segurança dos clientes e no trabalho. 


\section{SÍNTESE DE RESULTADOS DOS EMPREENDIMENTOS COM ADOÇÃO DA NORMA ABNT 15401}

Pesquisas realizadas com os primeiros empreendimentos que adotaram a norma revelam que a implantação de práticas sustentáveis garante a saúde financeira do empreendimento, gera renda para a população local e preserva o meio ambiente (PRADO, 2009):

a) $81,9 \%$ verificaram a melhoria dos resultados operacionais e financeiros da empresa;

b) 71,5\% ampliaram a viabilidade econômica do empreendimento;

c) $77 \%$ contrataram e treinaram trabalhadores da comunidade local;

d) $78 \%$ consumiram produtos e serviços da comunidade local;

e) $83,3 \%$ aumentaram a qualidade no atendimento e obtiveram mais satisfação dos clientes.

Os números mostram que o leque de possibilidades se abre àqueles que se propuserem a empreender dentro de uma ótica de sustentabilidade e valorização da comunidade local.

Outros parâmetros importantes e imprescindíveis de estudos futuros mais amplos são os indicadores de desempenho. No quadro que segue, extraído do Relatório de Gestão do Programa da Qualidade e Produtividade do Rio Grande do Sul - 2017, pode-se observar os avanços possíveis e as áreas a intensificar o empenho organizacional rumo à sustentabilidade com a aplicação de um sistema de gestão sustentável (SGA).

Quadro 1 - Indicadores sociais e ambientais da Empresa X

\begin{tabular}{|c|c|c|c|c|c|c|c|c|c|c|c|c|c|}
\hline \multicolumn{14}{|c|}{ 8.2 Sociais e Ambientais } \\
\hline \multirow[b]{2}{*}{$\mathbf{N}^{*}$} & \multirow[b]{2}{*}{ Indicador } & \multirow[b]{2}{*}{$\begin{array}{c}\text { Indicador } \\
\text { Apres. na PG }\end{array}$} & \multirow[b]{2}{*}{ E,OO. } & \multirow[b]{2}{*}{ Un. } & \multirow[b]{2}{*}{$\begin{array}{l}\text { Melhor } \\
\text { sentido }\end{array}$} & \multirow[b]{2}{*}{$\begin{array}{l}\text { Meta } \\
\text { ciclo } \\
\text { atual }\end{array}$} & \multicolumn{3}{|c|}{ Periodo } & \multicolumn{2}{|c|}{$\begin{array}{l}\text { Avaliação da } \\
\text { Competitividade }\end{array}$} & \multicolumn{2}{|c|}{ Avaliação do Compromisso } \\
\hline & & & & & & & 2014 & 2015 & 2016 & \begin{tabular}{|c|} 
Resultado \\
do RC \\
Ou \\
NA (Não \\
Aplicável) \\
\end{tabular} & \begin{tabular}{|} 
Nome da \\
organização
\end{tabular} & $\begin{array}{c}\text { Resultado do RPI } \\
\text { Ou } \\
\text { NA (Não } \\
\text { Aplicável) }\end{array}$ & $\begin{array}{c}\text { Parte Interessada } \\
\text { Pertinente }\end{array}$ \\
\hline 8.2 .1 & \begin{tabular}{|c|}
$\begin{array}{c}\text { Evoluçáo do Sistema de } \\
\text { Gestajo-Taxa de consumo } \\
\text { de recursos naturais (kze } \\
\text { agua) }\end{array}$ \\
\end{tabular} & 1 & $E / O$ & $\mathrm{~N}^{*}$ & $\downarrow$ & 5 & 3 & 3 & 2 & 5 & Empresa A & \begin{tabular}{|c|} 
Evoluçáa do \\
Sistema de \\
Gestáo: Inovaçáe \\
Sustentabilidade 4 \\
pontos \\
\end{tabular} & $\begin{array}{l}\text { Departamento } \\
\text { Regional }\end{array}$ \\
\hline 8.2 .2 & $\begin{array}{c}\text { Consumo de Energia } \\
\text { Eletrica }\end{array}$ & 1. 24 & 0 & Kwh & $\downarrow$ & 900.000 & 855.363 & 941.805 & 944.046 & 1.029 .600 & Empresa B & $\begin{array}{l}\text { Reduçáa de } \\
\text { consumo }\end{array}$ & Sociedade \\
\hline 8.2 .3 & Consumo de Agua & 1. 24 & $\circ$ & $M^{x}$ & $\downarrow$ & 28.000 & 29.344 & 26.795 & 31.045 & 21.634 & Empresa $\mathrm{A}$ & $\begin{array}{c}\text { Reduçàio de } \\
\text { consumo }\end{array}$ & Sociedade \\
\hline 8.2 .4 & $\begin{array}{c}\text { Consumo de Papel A4 - } \\
\text { Pacote } 500 \text { folhas }\end{array}$ & 24 & $\circ$ & Ret & $\downarrow$ & 430 & 507 & 437 & 498 & 448 & Empresa B & $\begin{array}{l}\text { Reduçáo de } \\
\text { consumo }\end{array}$ & Sociedade \\
\hline 8.2 .5 & \begin{tabular}{|c|} 
Consumo de Copos \\
Plásticos - Pacote 100 \\
unidades
\end{tabular} & 24 & $\circ$ & Pet & $\downarrow$ & 1.000 & 2048 & 2837 & 494 & 2715 & Enorocesa B & $\begin{array}{l}\text { Reduçáo de } \\
\text { consumo }\end{array}$ & Sociedade \\
\hline 8.2 .6 & $\begin{array}{c}\text { \% Pes5oas Beneficiadas } \\
\text { (DSL) [(N }{ }^{\circ} \text { de pessoas } \\
\text { beneficiadas na aça / } \mathrm{N}^{\circ} \\
\text { total da } \\
\text { comunidade) } \\
\end{array}$ & 24. 26 & $\circ$ & $\%$ & $\uparrow$ & $\begin{array}{l}\text { Acima } \\
80 \%\end{array}$ & 80 & 90,27 & 95.28 & 100 & Empresa A & $\begin{array}{l}\text { \% de Pessoas } \\
\text { beneficiadas } \\
\text { superior ao ano } \\
\text { anterior }\end{array}$ & Comunidade \\
\hline 8.2 .7 & $\mathrm{~N}^{\circ}$ entidades atendidas & 24. 26 & $\circ$ & $\mathrm{N}^{*}$ & $\rightarrow$ & 5 & 8 & 6 & 8 & 9 & Empresa A & $\begin{array}{l}\mathrm{N}^{\circ} \text { de Entidades } \\
\text { beneficiadas }\end{array}$ & Comunidade \\
\hline 8.2 .8 & $\begin{array}{l}\text { Quantidade de itens } \\
\text { arrecadados nas açóes }\end{array}$ & 24. 26 & $\circ$ & $\mathrm{N}^{\circ}$ & $\uparrow$ & $\begin{array}{c}\text { Acima } \\
\text { de } 1.200 \\
\text { itens }\end{array}$ & 1.573 & 1.344 & 1.887 & 1.034 & Empresa A & $\begin{array}{l}\mathrm{N}^{0} \text { de Itens } \\
\text { arrecadados }\end{array}$ & Comunidade \\
\hline 8.2 .9 & $\begin{array}{c}N^{\circ} \text { de pessoas atendidas } \\
\text { em açóes sociais }\end{array}$ & 24. 26 & $\circ$ & $\mathrm{N}^{*}$ & $\uparrow$ & $\begin{array}{l}\text { Acima } \\
\text { de } 1.000 \\
\text { pessoas }\end{array}$ & 1.633 & 1.287 & 1.887 & 1.887 & Empresa A & $\begin{array}{l}\mathrm{N}^{\circ} \text { de ltens } \\
\text { arrecadados }\end{array}$ & Comunidade \\
\hline
\end{tabular}

Fonte: Relatório de Gestão do Programa da Qualidade e Produtividade do Rio Grande do Sul, 2017. 
Observa-se no Quadro 1 a análise comparativa dos indicadores socioambientais da Empresa X, referentes a três ciclos de acompanhamento, 2014, 2015 e 2016. As Empresas A e B são consideradas referenciais comparativos pelo porte, performance e similaridade. Considerando os principais indicadores analisados para a pesquisa, pode-se inferir que:

a) consumo de energia elétrica: ocorreu devido ao aumento da taxa de ocupação hoteleira/aumento proporcional no último ciclo. Abaixo do referencial comparativo. A empresa utiliza lâmpadas econômicas;

b) consumo de água: apesar da instalação de válvulas redutoras de água nas torneiras de acesso aos hóspedes, houve um aumento considerável do consumo devido a um vazamento da água da piscina, encontrando-se acima do comparativo;

c) consumo de papel: acima do referencial comparativo. Foi verificado um plano de ação para a redução que prevê senhas para a utilização das impressoras e oficinas de aproveitamento do papel;

d) consumo de copos plásticos: diminuição considerável de copos plásticos no último ciclo de análise. Observou-se um plano de ação dentro da matriz swot dos setores da empresa, bem como a utilização de copos e xícaras de vidros por cada colaborador.

No quadro demonstrativo acima e nas considerações, foram ocultados os nomes reais das empresas analisadas para manter o sigilo, porém trata-se de dados reais, atualizados e demostram que, com desempenho e vontade institucional no estabelecimento de metas sustentáveis, é possível que todas as empresas do ramo de hospedagem possam também se preparar e estabelecer objetivos alcançáveis, do conhecimento do todos e que revertam em benefício, tanto para a instituição quanto para a sociedade e, principalmente, para o meio ambiente.

\section{CONSIDERAÇÕES FINAIS}

Cada vez mais, os empreendedores de turismo precisam estar atentos à gestão ambiental de suas empresas, não somente para a preservação dos recursos naturais, mas também pelo custo de utilização desses recursos.

A partir de pesquisas bibliográficas e das referências citadas, pode-se constatar que é totalmente viável a aplicação de um sistema de gestão ambiental, nos meios de hospedagens, 
em conformidade com a Norma ABNT 15401, melhorando, assim, seu desenvolvimento sustentável, além de se beneficiar com os resultados de desempenho ambiental da empresa. Tanto é assim que algumas pousadas e hotéis adotam programas de reuso de toalhas, tendo em vista que isso gera uma economia de água, energia e consumo de produtos de limpeza, além de contribuir para a durabilidade das toalhas.

Vale ressaltar que a adoção desse programa não deve impor ao hóspede essa obrigação, pois a manutenção dos serviços é um ônus da empresa e não do consumidor, que está pagando pela prestação destes serviços, até porque não é concedido nenhum desconto ao hóspede que adota este comportamento.

Vários são os modelos de programas a serem adotados pelas empresas de turismo, e que considerem questões de segurança e higiene, respeito ao consumidor, esclarecendo sempre o porquê da adoção dessa nova medida.

É necessário também que se realizem estudos ampliados para o acompanhamento da adoção das normas e a sua aplicabilidade, especialmente no que tange aos indicadores de desempenho pelos meios de hospedagem, tarefa que essas pesquisadoras se propõem ao desempenho.

Acredita-se fortemente que a educação ambiental deve fazer com que todos reflitam sobre os impactos de suas atitudes, para que os novos atos sejam incorporados pelos indivíduos.

\section{REFERÊNCIAS}

ASSOCIAÇÃO BRASILEIRA DE NORMAS TÉCNICAS. NBR 15401. Meios de Hospedagem - Sistema de Gestão da Sustentabilidade - Requisitos. Rio de Janeiro, 2006.

CAMPOS, V. F. Gerenciamento da rotina do trabalho do dia a dia. 8. ed. Belo Horizonte: Editora de Desenvolvimento Gerencial, 2004.

CAMPOS, V. F. Gerenciamento pelas diretrizes. Belo Horizonte: Fundação Christiano Ottoni Escola de Engenharia da UFMG, 1996.

DARNALL, N. et al. Environmental Management Systems: opportunities for improved environmental and business strategy? North Carolina: NDEMS, 2001. Disponível em: http://www.iso.org/iso/home/standards/certification/iso-survey.htm>. Acesso em: $2 \mathrm{dez}$. 2016.

INSKEEP, E. Tourism planning: an integrated and sustainable development Approach. New York: Van Nostrand Reinhold, 1991.

JOHNSTON, A.; SMITH, A. The characteristics and features of corporate environmental performance indicators - A case study of the water industry of England and Wales. EcoManagement and Auditing, Sydney, v. 8, p. 1-11, 2001.

ORGANIZAÇÃO MUNDIAL DO TURISMO (OMT). Indicators of sustainable development for tourism destinations: a guidebook. Madrid: WTO, 2004. 
PACHECO, A. P. R. et al. O ciclo PDCA na gestão do conhecimento: uma abordagem sistêmica. Disponível em: <http://isssbrasil.usp.br/artigos/ana.pdf> Acesso em: 26 jun. 2017. PINTO, T. P. Metodologia para a gestão diferenciada de resíduos sólidos da construção urbana. São Paulo, 1999. 189 f. Tese de Doutorado em Engenharia - Escola Politécnica, Universidade de São Paulo, São Paulo, 1999.

PRADO, T.; NUNES, M. Turismo a favor do planeta. Planeta Sustentável. São Paulo: Abril, 2009.

PGQP - PROGRAMA GAÚCHO DE QUALIDADE E PRODUTIVIDADE (RS). Relatório de Gestão do Programa da Qualidade e Produtividade do Rio Grande do Sul. Porto Alegre, 2017.

SEIFERT, E. K. EPE according to ISO 14031: Concept, Experience, and Revision Issues. In: HILTY, L.M.; SEIFERT, E.K.; TREIBERT, R. Information Systems for Sustainable Development. s.1.: IGI Global, 2005, 398p.

TOUR OPERATORS' INITIATIVE FOR SUSTAINABLE TOURISM DEVELOPMENT. Sustainable tourism: the tour operators' contribution. France, 2003.

VIEIRA, Elenara Vieira de. Desperdício em hotelaria: soluções para evitar. Caxias do Sul, RS: Educs, 2004. 